\title{
Outcomes of mitral valve repair for bileaflet prolapse
}

\author{
Yukikatsu Okada, MD, Michihiro Nasu, MD, Tadaaki Koyama, MD, Yu Shomura, MD, Mituru Yuzaki, MD, \\ Takashi Murashita, MD, Naoto Fukunaga, MD, and Yasunobu Konishi, MD
}

Objective: Repair of bileaflet prolapse has been considered to be technically demanding and challenging. To assess the reliability and durability of mitral valve repair for bileaflet prolapse, the present study compared the outcomes of mitral valve repair for bileaflet prolapse with those for posterior prolapse.

\begin{abstract}
Methods: From January 1991 to April 2010, 191 consecutive patients with bileaflet prolapse (group B) underwent mitral valve repair using a combination procedure of expanded polytetrafluoroethylene chordal reconstruction for anterior prolapse, resection suture technique with/without sliding technique for posterior prolapse, and ring annuloplasty. During the same period, 323 patients with posterior prolapse (group P) underwent standard mitral valve repair. Serial echocardiograms were obtained at discharge and 1,3,5, and 10 years postoperatively.

Results: The mean age in group B (54 \pm 15 years) was significantly younger than that in group $\mathrm{P}(61 \pm 12$ years). Survival, including hospital death at 10 years, was superior in group B (group B, $90 \% \pm 3 \%$; group $\mathrm{P}, 83 \% \pm 3 \% ; P=.046$ ). At 10 years, no significant differences were found between the groups in terms of freedom from recurrent mitral regurgitation of more than mild (group B, $89 \% \pm 3 \%$; group $\mathrm{P}, 90 \% \pm 2 \%$ ), freedom from reoperation (group B, $97 \% \pm 2 \%$; group $\mathrm{P}, 97 \% \pm 1 \%$ ), and event-free survival (group B, $79 \% \pm 5 \%$; group $\mathrm{P}, 83 \% \pm 3 \%$ ).

Conclusions: The reproducibility and reliability of mitral valve repair for bileaflet prolapse compares favorably with that of posterior leaflet prolapse. Early surgery might be recommended for patients with severe mitral regurgitation owing to bileaflet prolapse. (J Thorac Cardiovasc Surg 2012;143:S21-3)
\end{abstract}

Approximately $30 \%$ of the patients who require mitral surgery for severe degenerative mitral regurgitation (MR) have bileaflet (BL) prolapse. The repair of BL prolapse, including Barlow's disease, has been considered to be technically demanding and challenging. The development of reparative procedures, including chordal reconstruction with expanded polytetrafluoroethylene (ePTFE) sutures, and monitoring using intraoperative transesophageal echocardiography has enabled the achievement of acceptable surgical results for mitral valve repair since $1990 .{ }^{1,2}$ The repair procedure for posterior leaflet (PL) prolapse has become standardized, ${ }^{3}$ and, currently, early surgery is routinely considered for patients with PL prolapse. In patients with BL prolapse, however, the timing of surgery and reparability for all possible procedures is still unclear. The aim of the present study

\footnotetext{
From the Department of Cardiovascular Surgery, Kobe City Medical Center General Hospital, Kobe, Japan.

Disclosures: Yukikatsu Okada, Michihiro Nasu, Tadaaki Koyama, Yu Shomura, Mituru Yuzaki, Takashi Murashita, Naoto Fukunaga, and Yasunobu Konishi have nothing to disclose with regard to commercial support.

Presented at The American Association for Thoracic Surgery Mitral Conclave, New York, New York, May 5-6, 2011

Received for publication April 30, 2011; revisions received Oct 5, 2011; accepted for publication Nov 8, 2011; available ahead of print Dec 12, 2011.

Address reprints to Yukikatsu Okada, MD, Department of Cardiovascular Surgery, Kobe City Medical Center General Hospital, 4-6 Minatojimanakamachi Chuoku, Kobe 650-0046 Japan (E-mail: yukiok@kcho.jp).

$0022-5223 / \$ 36.00$

Copyright (c) 2012 by The American Association for Thoracic Surgery doi:10.1016/j.jtcvs.2011.11.014
}

was to review our early and late outcomes of mitral valve repair for BL prolapse.

\section{METHODS}

From January 1991 to April 2010, 191 consecutive patients who underwent mitral valve repair for BL prolapse (group B) were analyzed retrospectively. BL prolapse was defined at surgery as follows: (1) prolapse of the anterior leaflet and posterior leaflet with/without commissure prolapse and (2) prolapse of the anterior leaflet associated with commissure prolapse. During the same period, 323 patients with PL prolapse (group P) underwent mitral valve repair using a standard resection suture technique with associated ring annuloplasty. The mean age of the patients with BL prolapse was significantly younger than that of patients with PL prolapse (Table 1).

\section{Surgical Procedures}

After a median sternotomy and bicaval/aortic cannulation, the mitral valve was exposed through a right-sided left atriotomy. After assessing the whole mitral apparatus, quadrangular or triangular resection of the redundant and prolapsed posterior leaflet was performed. The height of the remaining posterior leaflet was reduced to less than $15 \mathrm{~mm}$ using a sliding technique or folding procedure. Chordal reconstruction using ePTFE sutures (CV-5) was performed to repair prolapse of the anterior mitral leaflet. Finally, a complete flexible ring or a flexible band was applied for ring annuloplasty after measuring the intertrigone distance and height of the anterior leaflet. Concomitant procedures, including tricuspid annuloplasty $(n=45)$, maze procedure $(n=29)$, closure of an atrial septal defect or patent foramen ovale $(n=8)$, coronary artery bypass grafting $(n=7)$, aortic valve repair $(n=3)$, and aortic valve replacement $(n=2)$ were performed in 66 patients $(35 \%)$ in group B. In group P, 110 patients (34\%) also underwent concomitant procedures, including tricuspid annuloplasty $(n=67)$, maze procedure $(n=34)$, coronary artery bypass grafting $(n=24)$, aortic valve repair/replacement $(n=9)$, closure of an atrial septal defect or a foramen 


$$
\begin{aligned}
& \text { Abbreviations and Acronyms } \\
& \begin{aligned}
\mathrm{BL} & =\text { bileaflet } \\
\mathrm{ePTFE} & =\text { expanded polytetrafluoroethylene } \\
\mathrm{MR} & =\text { mitral regurgitation } \\
\mathrm{PL} & =\text { posterior leaflet }
\end{aligned}
\end{aligned}
$$

ovale $(\mathrm{n}=8)$, graft replacement of an ascending aorta $(\mathrm{n}=6)$, and others $(\mathrm{n}=3)$. Using intraoperative transesophageal echocardiography, a second pump-run was required for patients whose regurgitant jet area was more than $2 \mathrm{~cm}^{2}$ or who had a regurgitant jet impinging on the ring.

\section{Follow-up}

Data on hospital mortality and valve-related events were collected as a part of the follow-up protocol. Long-term follow up was completed from October 2010 to January 2011 through questionnaires and telephone interviews with patients. In group B, follow-up ranged from 6 months to 16.7 years; the mean duration was $6.1 \pm 4.5$ years. The cumulative follow-up was 1160 patient-years. No patient was lost to follow-up. In group P, follow-up ranged from 6 months to 16.7 years; the mean duration and cumulative follow-up was $5.7 \pm 4.7$ years and 1826 patient-years, respectively. Oral anticoagulation therapy was continued for 3 months after surgery in all patients. In patients who were in sinus rhythm, anticoagulation therapy was discontinued 3 months after surgery. In patients with atrial fibrillation, permanent anticoagulation therapy was applied. Serial echocardiograms were available for 88 patients ( $86 \%$ of survivors) and 35 patients $(81 \%)$ at 5 and 10 years in group B, respectively. In group P, echocardiograms were available for 126 patients $(77 \%)$ and 45 patients $(67 \%)$ at 5 and 10 years, respectively. The grade of MR was classified as none/ trace, mild (1+), moderate (2+), and severe (3+) according to the American College of Cardiology/American Heart Association 2006 guidelines. ${ }^{4}$

\section{Statistical Analysis}

Descriptive statistics are reported as the mean \pm SD for continuous variables and as frequencies and percentages for categorical variables, unless otherwise noted. A comparison between the groups was done using an unpaired $t$ test for continuous variables and a chi-square or Fisher's exact test for categorical variables. Estimates of long-term survival or freedom from valve-related events were made using the Kaplan-Meier method. The difference between the Kaplan-Meier curves was evaluated using the logrank statistic. The results are reported in accordance with the accepted guidelines. $^{5}$

\section{RESULTS}

Although complex procedures were required in group B, no significant differences were found in terms of a second pump-run (group B, 17 cases; group $\mathrm{P}, 17$ cases; $P=.14$ ). Significant residual regurgitation was successfully reduced to none or trace by second pump-run in all patients. One patient died in the hospital in group B, for a mortality rate of $0.5 \%$. The cause of death was low cardiac output caused by previous myocardial infarction and low left ventricular ejection fraction. In group B, survival, including hospital death, and freedom from cardiac death rate at 10 years was $90 \% \pm 3 \%$ and $96 \% \pm 2 \%$, respectively. In group $\mathrm{P}$, the survival and freedom from cardiac death at 10 years was $83 \% \pm 3 \%$ and $92 \% \pm 2 \%$. Both survival and freedom from cardiac death in group B were significantly
TABLE 1. Clinical patient profiles

\begin{tabular}{lccc}
\hline \multicolumn{1}{c}{ Variable } & BL prolapse & PL prolapse & P value \\
\hline Patients (n) & 191 & 323 & \\
Age (y) & $54.1 \pm 14.6$ & $60.1 \pm 11.7$ & $<.0001$ \\
Male (n) & $125(65)$ & $181(56)$ & .035 \\
NYHA FC III-IV & $45(24)$ & $88(27)$ & .36 \\
Sinus rhythm (n) & $140(73)$ & $250(76)$ & .26 \\
Echocardiography & & & \\
LVEDD (mm) & $56 \pm 7$ & $55 \pm 7$ & .15 \\
LVESD (mm) & $35 \pm 7$ & $33 \pm 7$ & .001 \\
EF (\%) & $66 \pm 8$ & $67 \pm 8$ & .07 \\
LA (mm) & $47 \pm 10$ & $47 \pm 9$ & .99 \\
RVp (mm Hg) & $42 \pm 16$ & $45 \pm 15$ & .035 \\
\hline
\end{tabular}

Data presented as mean \pm standard deviation or numbers, with percentages in parentheses. NYHA FC, New York Heart Association functional class; $L V E D D$, left ventricular end-diastolic dimension; $L V E S D$, left ventricular end-systolic dimension; $E F$, ejection fraction; $L A$, left atrium; $R V p$, right ventricular pressure.

superior to those in group $\mathrm{P}(P=.046$ and $P=.041$, respectively). A total of 42 patients (18 patients in group B and 24 patients in group P) experienced a stroke after surgery. Of the 42 stroke events, 24 were minor, without any associated neurologic deficits, and 19 events developed in 390 patients with sinus rhythm preoperatively. The freedom from thromboembolic events rate at 10 years was $83 \% \pm 4 \%$ in group $\mathrm{B}$ and $89 \% \pm 2 \%$ in group $\mathrm{P}(P=.50)$, respectively. In 63 patients who underwent a maze procedure (29 in group B and 34 in group P), only 3 patients in group $\mathrm{P}$ had stroke events within 1 year. The induction of a maze procedure for atrial fibrillation significantly reduced the stroke events in both groups $(P<.002)$.

Serial echocardiograms showed that the freedom from MR rate greater than grade $1+$ at 10 years was $89 \% \pm$ $3 \%$ in group B and $90 \% \pm 2 \%$ in group P. No significant difference was found in terms of recurrent MR between the 2 groups. At 5 and 10 years, $81(92 \%)$ of 88 patients and $31(89 \%)$ of 35 patients who demonstrated none to MR grade $1+$ in group $\mathrm{B}$, respectively. In group $\mathrm{P}, 115$ $(91 \%)$ of 127 patients and $39(87 \%)$ of 45 patients had

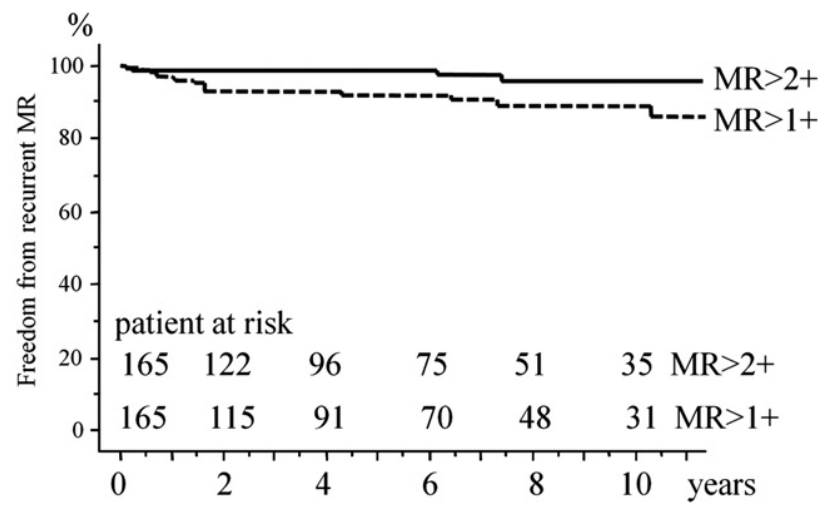

FIGURE 1. Freedom from mitral regurgitation $(M R)$ greater than grade $1+$ and grade $2+$ in group B. 
none to MR grade $1+$ at 5 and 10 years, respectively. The freedom from MR greater than grade $1+$ and MR grade $2+$ in group B is shown in Figure 1. Reoperation was required for recurrent severe MR in 3 patients in group B and 7 patients in group P. For the 3 patients who underwent reoperation in group $\mathrm{B}$, the procedure was performed at 1 month, 7.4 years, and 8.4 years postoperatively. Repeat repair was successful, except for the 1 patient whose leaflets were thick at 7.4 years postoperatively. The freedom from reoperation rate at 10 years was not significantly different between the 2 groups (group B, $97 \% \pm 2 \%$, and group $\mathrm{P}$, $97 \% \pm 1 \% ; P=.76$ ). The event-free survival rate at 10 years was $79 \% \pm 5 \%$ in group B and $83 \% \pm 3 \%$ in group $\mathrm{P}(P=.72)$.

\section{DISCUSSION}

In the present study, simple and standardized procedures, including resection and a suture technique for posterior prolapse and chordal reconstruction with ePTFE sutures for anterior prolapse, allowed us to achieve a very high repair rate and acceptable late results for BL prolapse comparable to those seen in PL prolapse. Since the introduction of chordal reconstruction using ePTFE sutures at our institution in 1991, we have strived to repair BL prolapse using a combination of resection and suture technique for posterior prolapse and chordal reconstruction using ePTFE sutures for anterior prolapse. Since 1991, the repair rate for BL prolapse has been $100 \%$. However, the development of intraoperative transesophageal echocardiography helped us to assess the results of mitral valve repair immediately after the procedure. Mohty and colleagues ${ }^{1}$ reported that greater reoperation rates were observed in patients with residual MR, even mild, noted during surgery. During our initial stages of learning mitral valve repair before 1991, we had a couple of experiences with mild residual regurgitation increasing and requiring reoperation within the first postoperative year; thus, we strictly apply the cutoff value of residual regurgitant signal to be less than $2 \mathrm{~cm}^{2}$. Also to avoid intravascular hemolysis after repair, regurgitant jet signals impinging on the ring were not considered acceptable. The incidence of a second pump run was comparable between the 2 groups. Depending on the site and mechanism of residual MR, additional procedures allowed us to reduce the MR significantly and successfully. We believe that complete repair, as demonstrated by good coaptation without residual MR, is essential in mitral valve repair.

Very long-term results of mitral valve repair have shown that significant differences are present in freedom from reoperation and freedom from recurrent MR of greater than grade $2+$ between patients who undergo mitral valve repair for anterior prolapse and PL prolapse. ${ }^{1,2,6}$ These reports include patients who underwent mitral valve repair without the use of transesophageal echocardiography. Chordal reconstruction with ePTFE sutures has expanded the reliability of mitral valve repair, especially for patients with anterior and bileaflet prolapse. ${ }^{2,6,7}$ This technique is not limited by the width and/or number of prolapse sites. ${ }^{8}$ Seeberger and colleagues ${ }^{9}$ recently reported that the longterm outcomes and reoperation rates for anterior mitral leaflet prolapse are not significantly different from those for PL prolapse or BL prolapse. Suri and colleagues ${ }^{10} \mathrm{dem}-$ onstrated that the durability of valve repair has improved during the past decade in all categories of mitral leaflet prolapse.

In the present era, because we can repair almost all categories of mitral valve prolapse, left ventricular function and valve-related morbidity and mortality after repair should be taken into account when considering the timing of surgery. Although follow-up of longer than 20 years is required to decide the optimal timing of repair for young patients with $\mathrm{BL}$ prolapse, repeat repair is possible as long as the pliability of the anterior leaflet remains.

In conclusion, the reproducibility and reliability of mitral valve repair for BL prolapse compares favorably to those of PL prolapse. To avoid valve-related morbidity and mortality after repair, early surgery might be recommended for younger patients with severe MR due to BL prolapse.

\section{References}

1. Mohty D, Orszulak TA, Shaff HV, Avierinos JF, Tajik JA, Enriquez-Sarano M. Very long-term survival and durability of mitral valve repair for mitral valve prolapse. Circulation. 2001;104:I-1-7.

2. David TE, Ivanov J, Armstrong S, Christie D, Rokowski H. A comparison of outcomes of mitral valve repair for degenerative disease with posterior, anterior, and bileaflet prolapse. J Thorac Cardiovasc Surg. 2005;130:1242-9.

3. Carpentier A. Cardiac valve surgery-the "French correction." J Thorac Cardiovasc Surg. 1983;83:323-37.

4. Bonow RO, Carabello BA, Chatterjee K, de Leon AC, Faxon DP, Freed MD, et al ACC/AHA 2006 guidelines for management of patients with valvular heart disease. Circulation. 2006;114:e84-231.

5. Akins CW, Miller DC, Turina MI, Kouchoukos NT, Blackstone EH, Grunkenmeier CL, et al. Guidelines for reporting mortality and morbidity after cardiac valve interventions. Ann Thorac Surg. 2008;85:1490-5.

6. Braunberger E, Deloche A, Berrebi A, Abdallah F, Celestin JA, Meimoun P, et al. Very long-term results (more than 20 years) of valve repair with Carpentier's techniques in nonrheumatic mitral valve insufficiency. Circulation. 2001;104 I-8-11.

7. Gillinov AM, Blackstone EH, Alaulaqi A, Sabik JF III, Mihaljevic T, Svensson LG, et al. Outcomes after repair of the anterior mitral leaflet for degenerative disease. Ann Thorac Surg. 2008;86:708-17.

8. Rankin JS, Orozco RE, Rodgers TL, Alfery DD, Glower DD. "Adjustable" artificial chordal replacement for repair of mitral valve prolapse. Ann Thorac Surg. 2006;81:1526-8.

9. Seeberger J, Borger MA, Doll N, Walther T, Passage J, Falk V, et al. Comparison of outcomes of minimally invasive mitral valve surgery for posterior, anterior and bileaflet prolapse. Eur J Cardiothoracic Surg. 2009;36:532-8.

10. Suri RM, Schaff HV, Dearani JA, Sundt TM, Daly RC, Mullany CJ, et al. Surviving advantage and improved durability of mitral valve repair for leaflet prolapse subsets in the current era. Ann Thorac Surg. 2006;82:819-26. 